Article

\title{
Linking Complexity and Sustainability Theories: Implications for Modeling Sustainability Transitions
}

\author{
Camaren Peter $^{*}{ }^{\dagger}$ and Mark Swilling ${ }^{\dagger}$ \\ School of Public Leadership, Faculty of Economic and Management Sciences, \\ Stellenbosch University, Private Bag X1, Matieland 7602, Western Cape, South Africa; \\ E-Mail: swilling@sun.ac.za.
}

$\dagger$ These authors contributed equally to this work.

* Author to whom correspondence should be addressed; E-Mail: camaren@smplxcty.co.za; Tel.: +27-(0)21-448-6803; Fax: +27-(0)82-447-1020.

Received: 28 November 2013; in revised form: 5 March 2014 / Accepted: 6 March 2014 / Published: 24 March 2014

\begin{abstract}
In this paper, we deploy a complexity theory as the foundation for integration of different theoretical approaches to sustainability and develop a rationale for a complexity-based framework for modeling transitions to sustainability. We propose a framework based on a comparison of complex systems' properties that characterize the different theories that deal with transitions to sustainability. We argue that adopting a complexity theory based approach for modeling transitions requires going beyond deterministic frameworks; by adopting a probabilistic, integrative, inclusive and adaptive approach that can support transitions. We also illustrate how this complexity-based modeling framework can be implemented; i.e., how it can be used to select modeling techniques that address particular properties of complex systems that we need to understand in order to model transitions to sustainability. In doing so, we establish a complexity-based approach towards modeling sustainability transitions that caters for the broad range of complex systems’ properties that are required to model transitions to sustainability.
\end{abstract}

Keywords: complexity; sustainability; resilience; decoupling; socio-metabolism; behavioral change; transitions; self-organization; emergence; undecidability 


\section{Introduction}

\subsection{Modeling, Complexity and Transitions to Sustainability}

"Most fundamentally, ecological and socio-economic systems are complex, adaptive systems, integrating phenomena across multiple scales of space, time and organizational complexity” [1] (p. 328).

The core theoretical foundations of sustainability, as a field of research and as a discipline, are still being developed, and a number of different, but mostly convergent theories — as argued in this paper-have emerged as theoretical frameworks for conceptualizing transitions to sustainability. This requires actualizing the mutual sustainability of linked human-environment systems. These linked social, economic, environmental, physical and political (SEEPP) systems are complex, adaptive systems [1,2]. Yet, what is still lacking is an approach or framework that helps integrate these theories and harnesses the different advantages of each through integrated modeling and analysis that adequately draws on complexity theory. In this paper, we investigate how complexity theory underpins key current sustainability theories, that is; theories of sustainability that focus on how transitions to sustainability may occur, or can be actualized.

Before we proceed, however, we must first clarify what we mean by “modeling”. The term "modeling”, as used in this paper, refers to both hard and soft systems' analyses and models, that is: (1) whether explicit and coded into computer models and simulations, mathematical models,. etc., or; (2) whether they consist of tacit mental models and broad scenario and strategic analyses. It is important to make this distinction between hard and soft modeling because both hard and soft systems' analyses are often required in order to deal with the full scope of complexities that constitute sustainable development challenges. In particular, modeling transitions to sustainability necessitates engaging both with existing systems, as well as the range of uncertain futures that the system must become sustainable in.

Emerging theoretical frameworks for transitions to sustainability include: (1) resilience theory; (2) decoupling theory; (3) the multi-level perspective (MLP) on transitions to sustainability; and (4) behavioral change theories of sustainability. All these theories of sustainability proffer valuable perspectives in respect of how modeling and analysis can be used to help decision-makers negotiate the complexity of the challenge of transitioning to whole system sustainability. Systems and complexity theory has been deployed in all of these theories, but to varying extents. The differences between them are due to differences in their conceptual foundations and the complex systems' properties they emphasize.

In this paper, we argue that the current theoretical approaches that seek to deal with the complexity of actualizing transitions to sustainability, do not fully appreciate the implications of complexity theory and hence remain restricted to modeling the mechanisms that drive the dynamic behaviors of complex systems (e.g., non-linear feedbacks, and leads and lags that are mediated by flows between stocks: see [3-5]). These are good at determining problems from a systems perspective, but not necessarily good for thinking about solutions. Moreover, by focusing on mechanisms that drive complex dynamics often only a subset of the properties of complex systems are addressed [5]. In order to think about, model and formulate, solutions, we argue that a more rigorous interpretation of how complexity theory meets theories that deal with sustainability transitions is necessary. 


\subsection{Why is Complexity Theory Important for Understanding and Managing Transitions to Sustainability?}

According to Loorbach and Rotmans [6], the role of complexity theory in understanding and acting upon transitions to sustainable development is central [6-9]. However, they also emphasize that the complex systems approach "should not be regarded as a straightjacket, however, but as an over-arching way of thinking (i.e., "umbrella”) within which other research approaches can fit”. They put forward a threefold rationale for "studying current and future transitions and system innovations", that is, as stated in [6]:

- (i) The transition domains of our research foci could be considered as complex systems themselves;

- (ii) The close and recursive relation between transitions and system innovations, which makes the complex systems approach an obvious choice;

- (iii) As a unifying principle, the complex systems approach offers a framework for synthesizing different knowledge strands which is necessary for addressing transitions and system innovations.

Hence, we use complexity theory as a framework for integrating between different theories of transitions to sustainability. Note that the integrative role that complexity theory can play is as a "unifying principle", and not as a "unifying theory". We argue that this "unifying principle" can be actualized as a plural, open-ended framework that is articulated through a thorough consideration of complex systems' properties.

Moreover, our framework is required to be able to help better understand and support transitions to sustainability, and hence, must match the adaptive management requirements for transitions adequately. These requirements are that adaptive management for transitions to sustainability are required to be "plurifocal, multi-scale, multi-level and adaptive" [6]. Most importantly, the modeling framework must support and facilitate the creation of a "shared understanding" of the complexities of transitions to sustainability through enabling participation [10-13].

\subsection{Goal and Outline of Paper}

The key question that we address in this paper is "what kind of complexity-based approach towards modeling sustainability challenges and transitions is necessary for dealing with transitions to sustainability?”.

We go about addressing it in the following manner. Firstly, as pointed out by Chu et al. [14] we acknowledge that no definitive "grand unified theory" of complexity exists, and that achieving a unified theory of complexity may not be possible. They [14] conclude that complexity-based approaches that seek to simplify complex systems and their behaviors has "limited scope" and "exaggerated claims of universality". They consequently propose that it is more appropriate to "look for new and complementary approaches to study complexity" and that "(O)ne such direction is to focus more on properties of complex systems, rather than the detail of mechanism” [14]; emphasis added.

So instead of formulating a unified theory of complexity and applying it to the challenge of modeling sustainable development challenges, we adopt a different approach, that is; one that focuses on complex systems' properties (see Section 2).

The reason complexity theory is important for understanding transitions to sustainability is that it can serve as a theoretical framework for integrating between different theories of sustainable 
development. We illustrate how in this paper. By themselves, these sustainability oriented theories separately emphasize and focus on different complex systems' properties. We identify the key properties of complex systems that resonate with different theories of sustainability (see Section 3). This analysis reveals which complex systems' properties different theories of transitions to sustainability emphasize, and reveals why the consideration of each theory is necessary (see Section 4). That is, they emphasize different complex systems' properties that are relevant to sustainability transitions (although there is overlap between them), but when taken together they address a broader span of complex systems' properties.

We argue that, as a consequence of the strong resonance between complexity and sustainability theories, it is necessary (and possible) to formulate a complexity-based framework for modeling sustainability challenges. We use these points of resonance (i.e., common complex systems' properties) between both theoretical frameworks to identify key modeling themes that are necessary for modeling transitions to sustainability; and propose a general, complexity-based framework for modeling transitions to sustainability on this basis.

We argue that four key considerations are necessary to enable a complexity-based approach towards modeling sustainability and transitions to sustainability (see Section 4). That is, a complexity-based modeling approach for sustainability must be:

- Probabilistic: embracing probabilistic methods for systems and agent interaction-in order to accommodate agency, non-linearity, uncertainty, multiple futures and multiple-scenario analyses.

- Integrative: integrating between linked human-environment systems-i.e., cross-scale, cross-sector, cross-level and inter-institutional; in order to integrate between systems, agents and networks at different scales to achieve whole system sustainability.

- Inclusive: participatory-based modeling - in order to accommodate multiple perspectives and understand undecidability, and to generate adaptive and innovative capacity.

- Adaptive: supporting adaptive modeling of transitions to provide decision-support to adaptive management efforts-i.e., it must be "heterarchical" in order to be able to adapt to real-world changes as they occur (i.e., in real or near-real time) with no need to completely re-formulate decision-making models (i.e., for lower transaction costs of modeling and quicker reaction times to emergent phenomena).

The outcome is a high-level framework that can inform the modeling choices that are taken by researchers and decision-makers who are concerned with complex sustainability transitions. By way of example we illustrate how the framework can be used to make key choices that inform the selection of modeling techniques, that is; so that the key, requisite complex systems' properties are addressed in the integrated modeling effort (see Section 5).

\section{The Conceptual Foundations of Complexity Theory}

In this section, we review the key concepts that underpin complexity theory, and the properties of complex systems. 


\subsection{The "Theory of the Multi-Agent System"}

Systems and Complexity: For the purposes of this paper, the definition of complexity theory that is used is stated as follows [15]:

"Complexity theory is the theory of the multi-agent system".

In defining complexity theory as the "theory of the multi-agent system", a very simple step is taken beyond conventional systems theory. In complexity theory, agency is attributed to all systems, sub-systems and sub-system components, and not just actors within the system. They all have the potential to rise to authority and dominate system-level behaviors depending on the particular conditions that govern system and its evolution (see Section 2.6). This goes a step beyond dynamic systems theory, which articulates systems as consisting of stocks, flows, leads, lags and non-linear feedbacks [16] (i.e., mechanisms), which when modeled, reveal the complexity of the system through accommodating feedback and non-linear effects within flows, and the evolution of stocks.

In dynamic systems theory, emergence is an outcome of uncertainty, and non-linear interactions between stocks, flows, leads and lags. These can be described through simple algebraic equations that form the basis of computer simulations. When the system is subjected to many iterations, and particular driver frequencies, emergent behavior can unfold. Labeled as "chaotic" behavior, it is not probabilistic, but deterministic, as far its modeling foundations are concerned.

Moreover, in systems theory (and in particular, dynamic systems modeling), classical science methods and techniques are deployed to frame the conceptual model of the system, and to understand the "emergent" system behaviors (i.e., which cannot be predicted). Complexity theory, however, accommodates the actions of agents, networks of agents and groups of agents $[8,14,15]$. That is, complexity theory is particularly concerned with how systems "self-organize" (and correspondingly, self-disorganize) in relation to structure, controls, functions, processes [17,18]. By attempting to integrate systems with agents, complexity theory provides a theoretical and conceptual framework that can potentially help merge natural science and social science methodologies. It is also concerned with tacking complex problems and challenges, which may be fraught with irreducibility and/or undecidability (see Section 2.4) in decision-making. Again, this is especially important when negotiating the choices around trade-offs that are required for enabling and catalyzing transitions to sustainability.

Hence we argue that complexity theory is suited to help better understand how and why emergence occurs in integrated human-environment systems and that it has special relevance for the framing and analysis of questions of sustainability.

\subsection{Emergence and Self-Organization}

In complexity theory, both self-organization and emergence are inter-related and enjoy multiple definitions that are not mutually exclusive, but differ significantly from each other to warrant further explanation.

One definition of emergence simply describes situations where the conceptual or mental model of a system fails, and the behaviors that emerge from the system do not match the projections made by the model in use. That is, in this case, emergence is the "surprise" that couldn't be predicted. Emergence is then the difference between the predicted ( $\{\mathrm{L} 1\})$ behaviors and observed behaviors ( $\{\mathrm{L} 2\})$ [19]. In this 
view, emergence is the disjuncture between expectation and observed reality (i.e., $\{\mathrm{L} 2\}-\{\mathrm{L} 1\}$ ). It relates to the ability (or lack of ability) to predict the behaviors of complex systems [20,21].

A second perspective defines emergence as a product of the accumulation of self-organization and disorganization within the system i.e., complexity as an outcome of non-linear and uncertain system dynamics that lead to emergent behaviors at the whole system scale [8,22-24]. This is an epiphenomenalist view (i.e., an unsatisfactory one; see later) [24]; which presumes that emergence can be explained solely by the detailed interaction of "things" (i.e., whether sub-systems, agents and so forth) in the system. In this view, emergence results from the "devil in the detail”, that is; the detailed interactions between agents and sub-systems within the system, and how uncertainty and non-linearity combine to produce unexpected behaviors at the whole system scale.

And yet a third perspective on emergence states that emergence is a result of the "different ways of looking” [25] at the behaviors of the system. Individual perceptions are inadequate to absorb the "whole" system in its entirety, and as a result, each individual experiences the "whole" in a fragmented manner. Islam et al. [25] refer to this as "perceptual emergence”. In this view, emergence is a product of the relativity of perspectives held by different agents within a system. The "whole" only exists as an ontological construct, but it cannot be fully observed and understood due the limits of observation and measurability. The first and third definitions of emergence overlap to some extent; in the third perspective we could refer to sets of predicted (i.e., $\{$ L1\}) and observed behaviors (i.e., $\{$ L2 $\}$ ) instead.

Similarly, the notion of "self-organization" also enjoys multiple interpretations. In particular, self organization can firstly be attributed to multi-agent adaptation where the interdependencies, functions, controls and processes of a system undergo changes that either: (1) helps the system retain its overall identity (i.e., increases its resilience) [26]; or (2) pushes the system into a fundamentally new regime, which can be predictable or may be a surprise (i.e., emergent). Secondly, similarly to "emergence", self-organization can also be attributed to different "filters" or "lenses" of observation that are imposed on the system [17]. In this perspective, the way in which a system can be understood to be self-organized can vary according to observer-subject duality, i.e., the inseparability of observer and subject or object that is "measured" or evaluated in one way or another [27].

As phenomena, both emergence and self-organization are defined in similar terms, i.e., that they are not just objective ontological phenomena, but can differ according to who is looking at it (or observing it), i.e., they can be subjectively assessed and defined. As such, their "technical complexity” (i.e., the complex interactions between agents, sub-systems, functions, controls and processes) and their "perceptual complexity" (i.e., their observer-subject duality or inseparability) both contribute to how the complexity of a system is observed, analyzed and understood. In short, stable self-organization is both a product of how consistent and recognizable the behavior of a system is, and in turn, this is also dependent on the product of what "filters of analysis" are imposed upon the system and its behaviors i.e., the conceptual frameworks of observation and analyses that are employed as diagnostic and prognostic tools. Both self-organization and emergence are defined in dual terms, that is: ontological and perceptual.

This duality, which is inherent in complexity theory implies that modeling complex systems requires going beyond merely understanding dynamic changes in the system but rather requires us to be able to understand the limits of the frameworks of analysis and methods of observation that are deployed. When this duality is acknowledged, a solely epiphenomenalist view of emergence is unsatisfactory. 
Although there are similarities, complexity theory differs significantly from social structuration theory. In social structuration theory [28], structure "is always both enabling and constraining, in virtue of the inherent relation between structure and agency". That is, social structure is a duality; in that it both drives the emergence of social structure and is a product of it [3].

In complexity theory it is not just social structure that is emergent, but also whole system behaviors that are emergent. That is; the emergence of social structure is not the same as the emergence of systems behavior. This is especially the case when considering complex transitions to sustainability that involve considering the sustainability of SEEPP systems as a whole (i.e., whether socio-ecological, social-ecological and/or socio-technical systems are concerned). A key point here is that agents in natural systems do not behave the same way as human agents, whose behaviors are driven by values, beliefs and norms [29].

They are similar, however, as in complexity theory, emergence is also defined in terms of a duality, i.e., it is both: (1) a result of agent-structure interactions; as well as (2) perceptual, due to different ways of looking at (or filtering) complex systems features and behaviors. That is, as pointed out by Baas and Emmeche [22], "The observational mechanism may be internal or external”.

\subsection{Stability, Adaptive Capacity and the Sub-Optimization Principle}

Stable self-organization of complex systems are also a product of trade-offs that are made at the sub-system level. According to Richardson [30], stable self-organization at the whole systems scale requires that sub-systems do not function optimally. This is referred to as the "sub-optimization principle” [30] and [31] (p. 93). This has significant implications for self-organization and adaptive capacity of systems. It implies that if all sub-systems function at optimal levels, then the whole system becomes unstable and indeed, unsustainable. In practice, where sustainability is concerned, it implies that if all sectors within a society operated at optimal levels in relation their sectoral objectives, and ignored the need for trade-offs between themselves, then whole system stability and sustainability would be compromised. In this respect, the adaptive capacity of a system —its ability to self-organize-is hence critical to ensuring both stability and sustainability of systems.

In order to better understand the "adaptive capacity" of a SEEPP system, we need to understand the full span of system configurations (i.e., in terms of structure, controls, processes and functions), that can lead to the same or similar behavioral outcomes (i.e., sustainable or un-sustainable SEEPP systems). This is termed "degeneracy" in quantum theory [32], i.e., degenerate system states lead to the same overall systems behaviors. In modeling terms this is referred to as "equifinality" [33] that is; equifinal models lead to the same system behavior and identity.

\subsection{The Included Middle and the Undecidable}

Lastly, complexity requires engaging with the "the logic of the Included Middle” [34,35]. The "logic of the included middle" refers to where dualism breaks down, and a phenomenon or a judgment or decision is caught between dual categorizations and cannot clearly be understood in dual terms. That is, it defies attempts at resolution. As previously alluded to, the central challenge of sustainability involves engaging with dual goals (e.g., ecological and anthropocentric), and dual concepts (e.g., self-organization and emergence, as explained earlier). Hence, it must necessarily engage with decisions 
that cannot be clearly defined in dual terms, for example; decisions that are both beneficial and sacrificial at the same time. Derrida refers to this as "undecidability" in political decision-making [36,37]. The undecidable or the "included middle", invokes the necessity of coping with fundamental contradictions that arise in conception, measurability, analysis, evaluation and decision-making in complex, real world systems. Resolving undecidability is key to obtaining agreement on how sectors can operate sub-optimally in relation to each other in SEEPP systems, and in turn, for ensuring that regime stability is ensured.

\subsection{Antifragility and Creative Capacity}

Antifragility is the ability/capacity to harness volatility and uncertainty for gain, and not merely to withstand volatility and uncertainty and remain unchanged [32]. Antifragility goes beyond merely adapting to exogenous shocks in order to maintain the "status quo". Rather, it requires us to model the potentials that may emerge from individual agents and groups, clusters or networks of agents (i.e., agency) by understanding their creative capacity for innovation, and what constrains agents and agency in society and the environment.

\subsection{Hierarchy and Heterarchy}

Complex systems also thwart attempts at defining their systems, agents and sub-systems in terms of hierarchies. Hierarchical taxonomies do not "fit" the behavior of complex systems, which can be fast-changing, non-linear and unpredictable. In complex systems, hierarchies change [38], and this contributes to the difficulty of the challenge of modeling them. Consequently, a more flexible taxonomic framework is required; i.e., one that can be adapted to reflect the change. The term that is used to describe flexible hierarchies of agents and sub-systems that comprise a system is termed "heterarchy". A heterarchy can be conceptualized as "fishnet" or a flat hierarchy in which "functions rise to authority" depending on context [39]. As such, it is a more appropriate framework with which to "track" the changing relationships and behaviors of complex systems. In a heterarchy, hierarchies can evolve.

\section{Linking Complexity to Emerging Sustainability Transition Theories}

In this section, we link complexity theory to emerging theories of sustainability transitions. The core theoretical concepts and complex systems' properties underlying each theory are briefly summarized in this section, and compared in Table 1.

\subsection{Cross-Comparison of Complexity and Sustainability Theories: Mapping Conceptual Foundations}

\subsubsection{Resilience and Resilience Theory}

Building on the definition tendered by Gunderson [40], Walker et al. defines resilience as the "capacity of a system to absorb disturbance and re-organize while undergoing change so as to retain essentially the same function, structure, identity and feedback” [26] (p. 1). In resilience theory, a social-ecological system can exercise its resilience either through; adapting to maintain itself in a 
particular regime, or by transforming to an entirely new regime. Hence, resilience theory seeks to understand the resilience of social-ecological systems, which is enabled through the "adaptive capacity" and/or "transformability" of the social-ecological system and which allows it to negotiate exogenous pressures, change and uncertainty through self-organization (i.e., of agents, internal structure, networked interdependencies, controls, functions and processes) and/or innovation.

In resilience theory, adaptability/adaptive capacity (see Table 1), enacted through adaptive management [2,40,41], is the "capacity of actors in a system to influence resilience" through self-organization [26], whereas "transformability" is the ability to generate novel system configurations (i.e., "new stability landscapes") through innovation [26]. In a complexity-based perspective, the resilience obtained through adaptive capacity is akin to sub-optimization (i.e., through self-organization of structures, processes, functions and networks within the system), while "transformability" is akin to the concept of "antifragility" (see Table 1). This requires going beyond resilience to shocks by drawing on the potential to innovate and generate new regime level trajectories through harnessing creative capacity (see Table 2). The MLP also acknowledges that regime level trajectories can be influenced by self-organization (i.e., adaptive capacity) and/or niche innovation (i.e., creative capacity) (see the next section and Table 2).

Resilience theory conceptualizes transitions between different social-ecological system regimes using the adaptive cycle (see Figure 1) to describe whole system level phase changes [26]. Moreover, systems at various scales can be characterized by adaptive cycles, and they exert cross-scale effects upon each other, which when taken together is termed "panarchy" [42,43].

Figure 1. Adaptive Cycle and Complexity Theory [44], adapted from [42,45]. KS1 to KS16 denote "knowledge sets" 1 to 16.

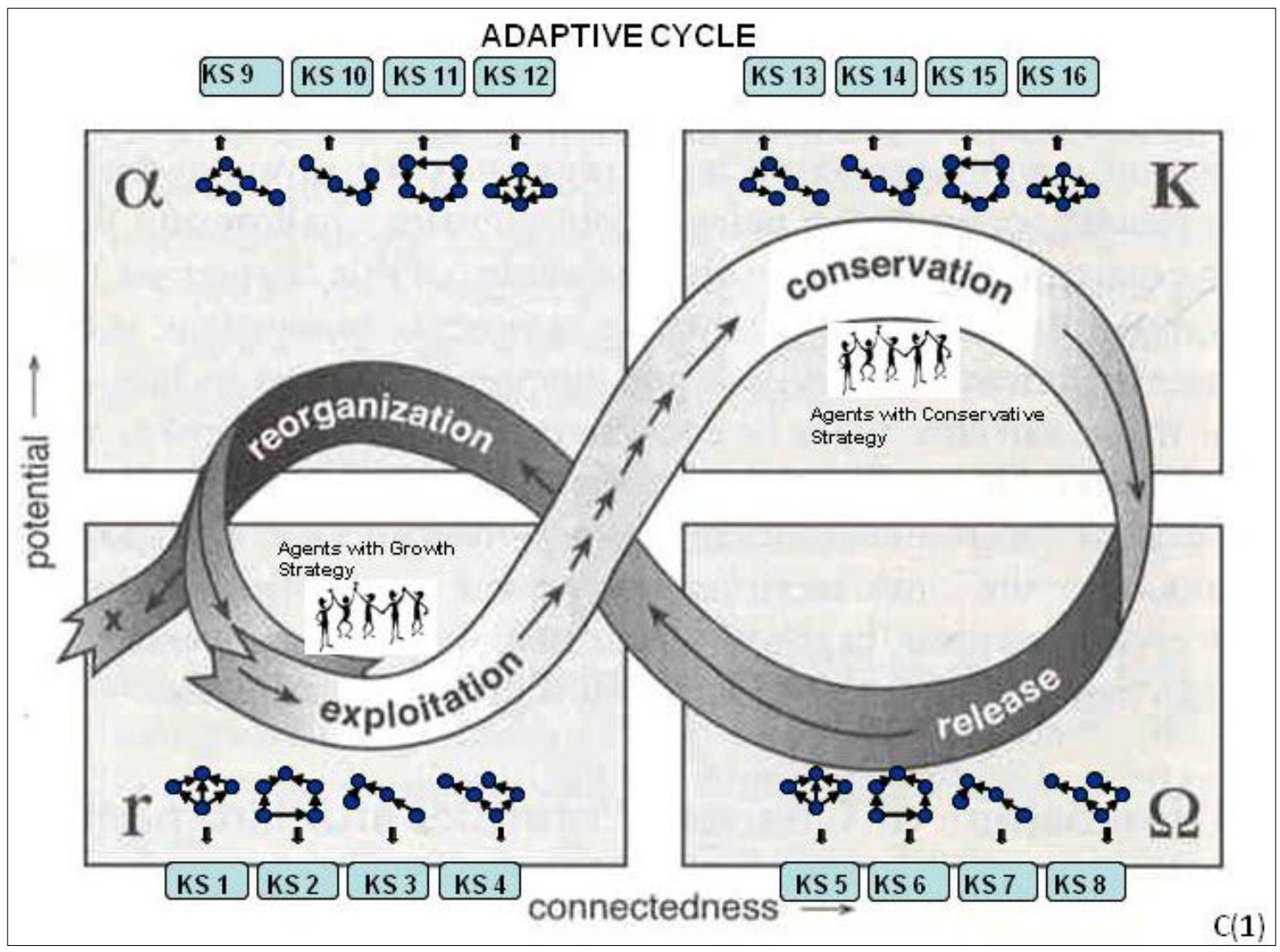


Table 1. Mapping conceptual foundations of complexity theory and complex systems' properties to theories of transition.

\begin{tabular}{l|l|l|l|l|l}
\hline \multicolumn{1}{c|}{ Theories } & $\begin{array}{c}\text { Complex System } \\
\text { Properties }\end{array}$ & Resilience Theory & $\begin{array}{c}\text { Multi-Level } \\
\text { Perspective } \\
\text { (MLP) }\end{array}$ & $\begin{array}{c}\text { Decoupling \& } \\
\text { Socio-Metabolic } \\
\text { Flows }\end{array}$ & $\begin{array}{c}\text { Behavioral } \\
\text { Change }\end{array}$ \\
\hline $\begin{array}{l}\text { Primary Theoretical } \\
\text { Concepts }\end{array}$ & Emergence & Resilience & Transition & Decoupled Growth & Social Change \\
\hline $\begin{array}{l}\text { Secondary } \\
\text { Theoretical } \\
\text { Concepts/Properties }\end{array}$ & $\begin{array}{l}\text { Self-organization; } \\
\text { Antifragility } \\
\text { Undecidability }\end{array}$ & $\begin{array}{l}\text { Adaptability/ } \\
\text { Adaptive capacity; } \\
\text { Transform-ability }\end{array}$ & $\begin{array}{l}\text { Landscapes, } \\
\text { regimes, niches } \\
\text { framework }\end{array}$ & $\begin{array}{l}\text { Socio-metabolic } \\
\text { flows; } \\
\text { Life cycle analysis; } \\
\text { Material flows } \\
\text { analysis }\end{array}$ & $\begin{array}{l}\text { Values, } \\
\text { beliefs, norms, } \\
\text { framewiors }\end{array}$ \\
\hline
\end{tabular}

Table 2. Mapping key modeling themes to complex systems' properties, and foundations of theories of transitions, to sustainability.

\begin{tabular}{|c|c|c|c|c|c|}
\hline $\begin{array}{c}\text { Key Modeling } \\
\text { Themes }\end{array}$ & $\begin{array}{l}\text { Complex } \\
\text { Systems' } \\
\text { Properties }\end{array}$ & $\begin{array}{c}\text { Resilience } \\
\text { Theory }\end{array}$ & $\begin{array}{l}\text { Multi-Level } \\
\text { Perspective }\end{array}$ & $\begin{array}{c}\text { Decoupling \& } \\
\text { Socio-Metabolic } \\
\text { Flows }\end{array}$ & Behavioral Change \\
\hline $\begin{array}{l}\text { Emergence 1: } \\
\text { Internal } \\
\text { Dynamics }\end{array}$ & $\begin{array}{l}\text { Uncertainty; } \\
\text { Non-linearity; } \\
\text { Agency }\end{array}$ & $\begin{array}{l}\text { Uncertainty; } \\
\text { Non-linearity; } \\
\text { Agency }\end{array}$ & $\begin{array}{l}\text { Uncertainty; } \\
\text { Non-linearity; } \\
\text { Agency }\end{array}$ & $\begin{array}{l}\text { Uncertainty; } \\
\text { Non-linearity; } \\
\text { Agency }\end{array}$ & $\begin{array}{l}\text { Uncertainty; } \\
\text { Non-linearity; } \\
\text { Agency }\end{array}$ \\
\hline $\begin{array}{l}\text { Emergence 2: } \\
\text { Perceptual }\end{array}$ & $\begin{array}{l}\text { Multiple } \\
\text { perspectives }\end{array}$ & Partial beliefs & Multiple levels & $\begin{array}{l}\text { Systems } \\
\text { perspective }\end{array}$ & $\begin{array}{l}\text { Plural basis for values, } \\
\text { beliefs, norms and } \\
\text { behaviors }\end{array}$ \\
\hline $\begin{array}{l}\text { Stability } \\
\text { Conditions }\end{array}$ & $\begin{array}{l}\text { Sub-optimization } \\
\text { Principle; } \\
\text { Degeneracy; } \\
\text { Undecidability }\end{array}$ & $\begin{array}{l}\text { Basins of } \\
\text { Attraction } \\
\text { (Limits \& } \\
\text { Thresholds); } \\
\text { Resilience; } \\
\text { Stability far } \\
\text { from } \\
\text { Equilibrium }\end{array}$ & $\begin{array}{l}\text { Regimes = } \\
\text { Stable Self- } \\
\text { Organization; } \\
\text { Normative } \\
\text { Aggregative } \\
\text { Systems }\end{array}$ & $\begin{array}{l}\text { Sustainability = } \\
\text { Decoupled Growth; } \\
\text { Flows/Fluxes into } \\
\text { system > } \\
\text { Flows/Fluxes out } \\
\text { of system }\end{array}$ & $\begin{array}{l}\text { Sustainability oriented } \\
\text { values, beliefs and } \\
\text { norms leading to } \\
\text { sustainable individual } \\
\text { and collective } \\
\text { behaviors }\end{array}$ \\
\hline Transitions & $\begin{array}{l}\text { Emergence and, } \\
\text { non-linear } \\
\text { change; } \\
\text { Self organization } \\
\text { and adaptive } \\
\text { capacity; } \\
\text { Antifragility, } \\
\text { innovation and } \\
\text { creative capacity }\end{array}$ & $\begin{array}{l}\text { Adaptive } \\
\text { capacity; } \\
\text { Transform- } \\
\text { ability; } \\
\text { Adaptive cycle }\end{array}$ & $\begin{array}{l}\text { Regime change } \\
\text { due to landscape } \\
\text { pressures and } \\
\text { niche evolution } \\
\text { and innovation }\end{array}$ & $\begin{array}{l}\text { Socio-metabolic } \\
\text { flows; } \\
\text { Life cycle analysis; } \\
\text { Material flows } \\
\text { analysis; } \\
\text { Limits and } \\
\text { thresholds }\end{array}$ & $\begin{array}{l}\text { Sustainability based } \\
\text { values and beliefs } \\
\text { become normative and } \\
\text { drive behavioral } \\
\text { change }\end{array}$ \\
\hline Hierarchy & Heterarchy & Panarchy & $\begin{array}{l}\text { Multiple levels: } \\
\text { micro (niche), } \\
\text { meso (regime) and } \\
\text { meta (landscape) } \\
\text { levels }\end{array}$ & $\begin{array}{l}\text { Systems within } \\
\text { systems, i.e., } \\
\text { embedded/nested } \\
\text { system }\end{array}$ & Agents and networks \\
\hline
\end{tabular}




\subsubsection{The Multi-Level Perspective on Transitions to Sustainability}

The multi-level perspective on transitions to sustainability is framed in terms of "socio-technical systems” (STS's), which are in turn comprised of three theoretical "levels". These levels can be described as follows [23,46]. Regimes (meso-level) constitute the "whole" of policy, regulatory, structural, institutional, societal and environmental systems that are normative at a particular scale or level of description, and as such constitute the "system" that is evolving and changing. Landscapes (meta-level) exist at larger scales (e.g., the global scale), and exert landscape pressures upon the regime, which the regime has little or no control over under most circumstances and must adapt to. Niches (micro-level) are embedded within the regime, but are spaces of innovation (whether technological, discursive or policy and so forth). Regimes are impacted by exogenous "landscape" pressures that emerge from regional and global influences. Landscape pressures open up spaces within the regime for change to occur. These changes are driven by niche developments, which occur within the socio-technical system. As niches accumulate and penetrate at the regime level, regimes begin to transition to different modes of operation (i.e., in terms of functions, controls, processes, systems and flows) and behavior at the meso-level

\subsubsection{Decoupling Theory}

The theory of decoupling proposes that sustainability should be orientated around strategies and actions to decouple growth (i.e., economic and population growth) from resource exploitation and environmental impacts [47]. The theory involves making use of methodological tools such as life-cycle analysis and material flow analysis to understand how transitions to "stronger" decoupled growth may be actualized. That is, it is concerned with orientating the "socio-metabolism" of socio-ecological systems at different scales (i.e., national, provincial, city, municipality) towards sustainability in terms of the flows of resources in the system. It involves closing socio-metabolic material flow loops, (for example in water, waste, nutrients, carbon, and so forth) and increasing efficiencies through the use of renewable energies, water re-use and recycling, agro-ecological production, and so forth. The strength of decoupling theory is that it relies on explicitly empirical foundations in order to implement and actualize. It is both measureable and empirical.

Decoupling theory deploys material flows and life-cycle analysis as a means to understand how system limits and thresholds will evolve over time under different projected future scenarios (see Tables 1 and 2). That is, material flow and life-cycle analysis is deployed as a proxy framework for evaluating stability conditions and resilience of the system. From a complexity and systems perspective, decoupling theory essentially adopts a mechanistic systems view that aims to provide an empirical basis for facilitating and guiding strategies for transition to sustainability (e.g., through quantifying domestic material and energy consumption levels). In this conception of sustainability, improving efficiency criteria of growth is fundamental to adequate transition, as well as balancing efficiency criteria with sub-optimization (see Table 1 and 2) for whole system sustainability. 


\subsubsection{Behavioral Change Theory}

Behavioral change theories for sustainability emphasize that transitions to sustainability require behavioral change, which in turn requires changes in the values, beliefs, norms and behaviors that govern society and its interactions with natural systems, and their mutual evolution [29,48]. That is, for example; behavioral patterns that govern consumption, resource exploitation, production and waste. Hence, understanding what frames the values, beliefs and norms that generate behaviors at individual and collective levels is hence critical for formulating actions towards sustainability [49].

From a complexity theory perspective, behavioral change theories for sustainability essentially describes how agents, and groups and networks of agents influence system or regime level behaviors through social changes that result from self-organization (see Tables 1 and 2).

\subsubsection{Complex Systems’ Properties}

Note that a large number of the primary and secondary theoretical concepts accounted for in Tables 1 and 2 are also properties of the respective systems that are conceptualized in each theory. For example, "feedback" is a systems mechanism, while "non-linearity" is a property of feedback. Likewise, emergence, self-organization and antifragility are also properties of complex systems. Likewise, resilience, adaptive capacity and transformability are also properties of resilient social-ecological systems. In MLP theory, landscapes, regimes and niches have distinct properties (as previously discussed) that relate to their roles in transition. In decoupling theory, the properties of socio-metabolic flows result in growth that is decoupled from resource exploitation and ecological degradation. Lastly, in behavioral change theory of social transitions to sustainability, values, beliefs, norms and behaviors are properties of social systems. Moreover, social change depends on complex systems' properties such as networks and agency at individual and group levels.

\subsection{Cross-Comparison of Complexity and Sustainability Theories: Key Modeling Themes}

Table 2 categorizes complex systems' properties and complexity-based concepts in terms of which sustainability transition theories they are emphasized. It categorizes them according to key, over-arching modeling themes. These were selected because they consist of a convenient, broad categorization schema for grouping complex systems' properties that are associated with transition, yielding a framework that is suitable for cross-comparison of complexity and sustainability theories (see Table 2 below). Within this framework, we identify what elements are required, from a complexity theory-based perspective, in order to address the challenge of modeling transitions to sustainability of complex SEEPP systems (see Sections 3.2.1 to 3.2.5). These elements emerge from a cross-comparison of the complex properties that are emphasized (or manifest) in different theories of transition to sustainability.

\subsubsection{Emergence 1: Internal Dynamics}

In this conception of complexity, emergence is driven by interactions between sub-systems and agents within the system that can be uncertain and/or non-linear in nature. System dynamics (i.e., in terms of external influences as well as internal change effects) take precedence over system history and memory; simply understanding how the system has behaved in the past, is no guarantee that we can 
predict the behaviors that may manifest in the future. That is, the ability to make linear predictions over system futures may break down where complex systems are concerned [24]. Instead, multiple futures must be envisaged and kept in mind when negotiating future strategic trajectories [50].

This suggests that a probabilistic, adaptive framework for reasoning and modeling systems with strong discontinuity/non-linearity and uncertainty [51,52], which results from multi-agent system interactions in both social and ecological systems is required.

\subsubsection{Emergence 2: Perceptual}

The fact that resilience theory acknowledges the existence of "partial beliefs" that govern how social-ecological systems are understood, implies that there will inevitably be conflicting understandings of social-ecological systems, and especially where decision-making over how to achieve sustainability is concerned. This is compatible with the notion of "perceptual emergence" described earlier in Section 2.2 [25]. Moreover, it is inevitable that some decisions will be undecidable in this respect, as clear "right” and "wrong” decisions may be unrealizable. In this sense, decision-making will require the facilitation of a fair amount of learning, participation, negotiation and cooperation amongst competing interests and the parties that represent them [11].

Hence, the need for facilitated processes that are inclusive and integrative is evident, as incorporating multiple perspectives/partial beliefs and integrating them is essential to sustainability transitions [42,53], so that a shared understanding of different perspectives and undecidability is maintained in modeling efforts.

\subsubsection{Stability Conditions}

Resilience theory essentially combines systems theory with the stable attractor concepts that were discovered and developed in chaos theory [42,54], in order to address questions about how the stability of "social-ecological systems" can be achieved [26,54], and to determine critical limits and thresholds beyond which system behaviors can become unstable. Resilience theory invokes the notion of a "basin of attraction" in defining resilience.

Here, stability occurs far away from equilibrium conditions, and is maintained through feedback mechanisms in the system that allow the system to correct within the amount of time required in order for the system to retain its "identity" i.e., the recognizable behavior it is associated with. So when feedbacks change drastically, the system or "regime" can change in abrupt, non-linear ways, leading to a transition to a new regime. These changes in feedbacks may occur through adaptability (i.e., self-organization of controls, functions, processes, interdependencies, etc.), through transformability (i.e., through re-organization), or alternatively due to unforeseen (often undesirable) changes that fundamentally alter regime trajectories (e.g., "black swans”) and which lie outside the controls of the regime [55].

Moreover, from a complexity theory perspective, stability is achieved through making slight adjustments within the system [30]. It is comparable to spinning a basketball on a single finger; slight but highly trained adjustments keep the ball spinning. These "highly trained" adjustments (or feedbacks) can take on different dimensions, and the set of adjustments that help a system retain its recognizable "identity" and behavior will be referred to as "degenerate states", that is, different 
adaptation configurations (i.e., states) within a stable regime. These adjustments usually involve the actions of an agent, or a group or network of agents that engage in "self-organization" to adapt to changes.

Note that in both resilience theory and the MLP, whole systems (i.e., whether social-ecological systems or socio-technical systems, respectively) are referred to as "regimes" [26,46]. Regimes are an articulation of the stability conditions of socio-technical systems and social-ecological systems, under which a recognizable system "identity" is maintained i.e., for a system that is at the same time evolving and changing, although retaining its identity at the same time. As a stability condition, the "regime" is perceptual, that is; in both resilience and MLP theories.

In decoupling theory, resilience and stability are conceived in terms of decoupled system growth along the life-cycle of the system. That is, sub-optimization is contingent on closing socio-metabolic loops or improving the efficiency of resource use. The need for integration and coordination of sub-system efficiencies and interdependencies is clear in this respect. Moreover, in order to achieve sub-optimization, integration and coordination a fair amount of undecidability can be expected in respect of what trade-offs are acceptable to different sectors of society in actualizing sub-optimization. Moreover, behavioral change theories for sustainability also invoke the need for learning, participation, negotiation and integration between different sectors of society [11] in negotiating changes in values, beliefs and norms that drive behaviors.

In respect of stability conditions, the need for integration, inclusion and coordination is clear, and the need to deal with trade-offs (i.e., sub-optimization and undecided-ability) must be accommodated.

\subsubsection{Transitions}

In both human and environmental systems, agents also deploy strategies of self-organization to mediate exogenous pressures over which they have no control (e.g., species migration). In the case of environmental systems, environmental system thresholds and limits also dictate the extent to which a natural system can absorb pressures, and when limits are breached, the system enters transition and/or "flips" to another state [26]. The metaphor also holds for human systems, and describes economic growth, stability, instability, collapse and regeneration. In resilience theory, the adaptive cycle (see Figure 1) is deployed as a metaphor, that is; it is a heuristic, conceptual framework for understanding how regime changes occur in "social-ecological systems" [56]. As shown in Figure 1, the transition between regimes (which may be continuous or non-linear and discontinuous) and stability conditions are articulated through the $\mathrm{r}$ (exploitation), $\mathrm{K}$ (conservation), $\Omega$ (breakdown) and $\alpha$ (renewal) phases of the "adaptive cycle", while degenerate states within each regime are represented by the "knowledge sets” associated with each regime [44].

In the MLP, regime transition is intimately dependent upon influences that emerge from the landscape and niche levels, which are ultimately direct drivers as well as complex processes that are in operation at different scales and levels. Modeling the sustainability of linked SEEPP systems requires that the notion of "antifragility" be carefully considered [32]. In particular, assessing the creative capacity that lies within niches is particularly important for understanding how niche evolution may drive regime transition.

In respect of the decoupling theory and the MLP, material flows' analysis and life cycle analyses hence provide the levers for transition, i.e., the adaptive capacity. In this respect, merging material 
flow analysis systems models (for decoupling) with transition analysis is critical for decision-making that seeks to achieve sustainable development [57]. This is because negotiating transitions to sustainability effectively requires a basic understanding of what critical limits and thresholds are in place, and how they may change with different transition scenarios.

In behavioral change theories, when the absorption of new values, beliefs and norms is high (i.e., discursive niches), and regime-level behaviors are recognizably different (i.e., in terms of absorption into policy, regulations, controls, functions, processes, etc.), then a regime has behaviorally transitioned. Understanding the evolution of norms is hence critical to understanding transition [48].

In summary, in respect of transitions, there is a need to understand the: (1) adaptive capacity for self-organization; (2) creative capacity for innovation; and (3) values, beliefs and norms of a system and their evolution $[1,48]$.

\subsubsection{Hierarchy}

In resilience theory, hierarchy is conceptualized as a "panarchy" of adaptive cycles. "Panarchy" is composed of many adaptive cycles operating at different scales, with significant cross-scale linkages [58]. Meta-stability is maintained through intra-system adaptive capacity, which allows for diverse forms of self-organization, that is; the degeneracy referred to earlier [32,44]. In the MLP, the macro (landscape), meso (regime) and micro (niche) levels also ascribe a complex system that is multi-level and multi-scalar. It accommodates cross-scale effects from both the landscape and niche levels, as well as within the regime level. That is, both the MLP and resilience theory articulate a heterarchical perspective on system change and transition.

Negotiating transitions to sustainability in multi-scale, multi-level and multi-agent SEEPP systems necessitates engagement across different levels of society. Decoupling theory is integrative in terms of mechanisms (i.e., in terms of stocks, flows, leads, lags, sectors and scales), and attempts to incorporate multiple levels and scales through embracing a systems perspective. However, decoupling theory is not explicitly inclusive. When efforts to decouple growth from environmental impacts and resource exploitation are formulated at the policy and programmatic levels, the need for inclusion becomes necessary, as without negotiating the various trade-offs and potential impacts that sustainability transitions may have across sectors and scales, adversely affected parties may resist transition (resulting in undecidability).

Behavioral change can be non-linear i.e., it is not always incremental or hierarchical. In this respect, the multi-level perspective provides a useful perspective on how behavioral change is induced. Discursive niches that emerge in response to regime level opportunity spaces resulting from landscape pressures are key to seeding, catalyzing and embedding new values, behaviors and norms that eventually penetrate at the regime level and catalyze broad-scale behavioral change. Note that niches are not hierarchically restricted; discursive niches (e.g., climate change) can act across scales and levels, that is, they have "heterarchical" reach.

Where hierarchy is concerned, the need to accommodate heterarchy highlights the need to understand and act upon cross-scale, cross-sector and cross-institutional interdependencies (i.e., vertical and horizontal integration) through: (1) inclusion and (2) heterarchical frameworks of reasoning and visualization of interdependencies. 


\section{Requisite Elements of a Complexity-Based Approach}

From the discussion of modeling themes held in the previous section, we distill and identify a set of requirements for our complexity-based modeling approach. We interpret these as a set of requisite elements (see below), which we position the proposed modeling framework around. We do not prescribe a single particular modeling methodology because mixed methods are more likely to be effective in addressing diverse and complex sustainability challenges. Rather the proposed framework informs how the selection of modeling methods should take place i.e., what elements should be accommodated for a holistic, complexity-based approach to be enabled (see Section 5).

\subsection{Probabilistic and Adaptive: From Hierarchical and Deterministic to Heterarchical and Probabilistic Models}

Probability theory-based statistical methodologies and analyses are required for modeling the complexity of SEEPP systems. This is because non-linear feedbacks and other higher order effects reside mainly in the "line wings" of the probability distribution. When probability distributions are "linearized" (e.g., in maximum likelihood based statistical analysis), the line wings are omitted from analysis. Hence, the conditions under which non-linear and higher-order functions take effect are lost from analysis.

Moreover, models that are formulated using through "hindcasting” (e.g., maximum likelihood based statistics), rely on the notion that past trends remain continuous with future trends and no major "surprises" emerge (i.e., the future can be predicted from the past). Hindcasted models become rigidly constrained for a particular purpose and scenario. This is problematic in the case of the complex adaptive systems, as models need to cater for degeneracy, regime transformations and emergence, and cannot be locked in (or constrained to) an inflexible single purpose model [59].

Lastly, probability theory is fundamentally concerned with explanation, as conditionality is essential to assign probability to a particular proposition (i.e., that may be true or false) [60]. Hence, it can serve as a basis for learning and engendering shared understanding of different perspectives on transition i.e., inclusion.

In summary, a probabilistic approach is required to accommodate uncertainty and non-linearity. Moreover, it is also required to be flexible and adaptive, so that it can accommodate learning, as well as a wide variety of possible endogenous and exogenous change effects. Hence, we propose that modeling approaches that are probabilistic, adaptive and heterarchical are required to accommodate these requirements.

\subsection{Integrative}

Hierarchies in complex systems may change dynamically as the system evolves; as a result of changes in temporal, spatial changes, changes in scales of aggregation, or due to emergence. In that respect, modeling approaches are required where functions can rise to dominance within a networked hierarchy i.e., where the hierarchy of a system can change and evolve. That is, a heterarchical modeling framework is required where modelers can re-arrange hierarchies and causalities as contextual, structural and taxonomic changes unfold. This is important if modeling frameworks are to 
be adaptable to changing real-world changes, and to accommodate, for example: (1) real-time and near-real time simulation; and (2) real-time and near-real time learning and adaptation; while (3) aid in understanding and monitoring changes in critical limits and thresholds of linked SEEPP systems.

Moreover, in respect of integration, both quantitative (e.g., statistics, data) and qualitative information (e.g., expert opinion, case studies and narrative analyses) must be integrated in modeling frameworks (e.g., such as behavioral analyses) [18,33,61]. In this respect, probabilistic modeling frameworks are required that can articulate (and visualize) how causalities (i.e., including flows, influences, etc.) between qualitative and quantitative variables integrate in different scenarios.

In respect of integration, we need to understand how cross-scale and cross-sector influences, as well as intra-regime dynamics, critical limits and thresholds, combine with the processes that underlie behavioral change to facilitate transition in environments where there is incomplete knowledge and high levels of uncertainty and change (i.e., "organizational whitewaters”) [52,62]. In this respect, we propose that a heterarchical, adaptive framework that can accommodate quantitative and qualitative inputs is required.

\subsection{Inclusive}

In respect of inclusion, there is a need to accommodate multiple and diverse perspectives on issues related to: (1) how SEEPP systems integrate; (2) what actions/strategies for negotiating change should be taken (i.e., in terms of what adaptations and/or innovations to adopt); (3) generating strategies for adaptation and innovation (i.e., adaptive capacity and creative capacity respectively) through participation and exchange; and (4) in respect of resolving undecidability that may arise over the complex trade-offs that are required in decision-making for sustainability.

Inclusive, participatory-based modeling approaches that accommodate multiple voices and narratives [18,61] are required, i.e., from multiple sectors, institutions and scales of influence. Strategy-making, narrative approaches, mental modeling, debate, dialogue and discussion are required in order to grapple deeply with complex decision-making challenges. Moreover, both the adaptive capacity and creative capacity of real-world agents and networks of agents can be harnessed in multi-sector, interdisciplinary and multi-level participatory engagements where scenarios and adaptation strategies are assessed. In this respect, modeling processes are required to accommodate processes of learning, participation, integration and negotiation [11]. Facilitating inclusion in modeling processes invokes the need for modeling processes that are facilitated by visualization frameworks that a variety of participants can interact and reason with.

This extends agent-based modeling beyond computer-based modeling of rule-based agents within systems to the inclusion of real-world agents, who are more adept in understanding and negotiating real-world complexities due to their lived experience and learning [33].

\section{Proposed Modeling Framework: Description and Benefits}

\subsection{Detailing Implementation Requirements of Proposed Modeling Framework}

In this section, we make explicit what considerations would be necessary for modeling transitions to sustainability, given the framework that we propose. Moreover, by way of example, we illustrate the 
usefulness of the framework: (1) in performing diagnostics of complex properties that a modeling technique (or a group of them) address (see Table 3 and Figure 2); and (2) in establishing shared understanding of how complex system properties drive complex behaviors that manifest in transition through following the prescribed model formulation and implementation process (see Figure 2).

We propose a modeling framework that does not prescribe modeling techniques (e.g., scenario-making, soft systems analysis, dynamic systems models, agent-based dynamic systems models, Bayesian networks, agent-based Bayesian networks) but rather provides a framework in which these techniques can be complementarily deployed, or within which specific choices can be made to match particular techniques to particular properties of complex systems.

No one particular modeling technique can account for all the properties of complex systems, so we argue that a collection of equifinal and non-equifinal models are necessary in order to cater for multiple perspectives of the current status of regimes, as well as future projections.

In practical terms, the proposed modeling framework can be further elaborated and detailed as follows; it is required to be:

Probabilistic, in respect of:

- Scenario-making and testing that deals with multiple futures, that is; multiple drivers exerted from the landscape level, as well as the multiple potential configurations of regimes [50]. In this case, we are referring to processes of dialogue and debate, narrative analyses [61], as well as visioning and visualization of multiple futures and scenarios (i.e., "soft” systems analysis) [50].

- Probability theory-based analytical frameworks are necessary, i.e., that accommodates whole probability distributions, so that non-linearity is preserved in analyses, as opposed to deploying analytical techniques that linearize out non-linear interdependencies from analyses and lose complexity. In this case, we are referring to "hard" systems techniques that makes use of full probability distributions in the actual modeling formalism itself, that is; whether frequentist (i.e., statistical) or subjective (i.e., inductive) probabilities [63,64] are used in modeling efforts.

Integrative, that is:

- It must integrate between different systems, agents, scales, levels of description and decision-making options/variables.

- It must be heterarchical so that it can integrate across scales and levels of description, and allow for the emergence of different configurations of controls, structures and processes as dominant drivers of whole system behavior.

Inclusive, that is:

- It must accommodate multi-participant modeling processes, where stakeholders, decision-makers and researchers can jointly interrogate scenarios, interventions, adaptation strategies, narratives, and so forth.

- In turn, this requires that visualizations of models are required that can help build shared understanding, particularly between stakeholders and decision-makers.

o This is essential for decision-making, i.e., where negotiation and debate around what options exist for how whole systems can be sub-optimized. 
o It is also essential for generating strategies for self-organization in response to the need for systemic adaptation to exogenous pressures (e.g., global economic and climate change effects) and/or endogenous change effects (such as niche transitions to regime level).

Adaptive, that is:

- Modular: "cut and paste" style modeling frameworks (i.e., object oriented software and visualizations/user interfaces) are required, so that models can be quickly adapted to reflect emergent change effects (i.e., both exogenous and endogenous) that influence system behavioral trajectories, as well as to accommodate the need to devise different strategies to respond to emergence.

- Evolutionary: near real-time and real-time modeling capabilities are required in order to allow for models to be able to be linked to real-time databases.

- Heterachical modeling frameworks are required, so that it accommodates emergence i.e., where different groups of functions, controls, structures and processes can "rise to authority" and dictate systems behavior.

Moreover, as illustrated in Table 3, the proposed modeling framework accounts for what high-level considerations need to be made, when considering what modeling techniques are appropriate, so that the collection of techniques that are used adequately account for the full span of complex systems' properties we are concerned with.

\subsection{An Example of How the Framework Can be Used to Evaluate a Set of Modeling Techniques for a} Particular Sustainability Transition Modeling Challenge

Each modeling technique that is used can be assessed by evaluating the extent to which it services the two dimensions of Table 3. For example, if we were to consider the use of Agent-Based Bayesian Networks (ABNs), Bayesian Networks (BNs), Agent-Based Systems Dynamics Models (ASDs), and Systems Dynamics Models (SDs) for the purpose of modeling a particular sustainability transition that we are concerned with, then Table 3 can be used to locate these techniques within the complexity-based modeling framework we propose.

Note that both soft and hard systems considerations must be made when considering whether a particular modeling technique fulfils the requirements of Table 3. For example, if we consider systems dynamics models and Bayesian networks:

- When considering whether Bayesian networks and systems dynamics models are probabilistic in how they address “emergence and self-organization” (see Table 3 and Figure 2):

o Bayesian networks would be considered probabilistic because they directly model whole probability distributions that preserve non-linearity i.e., in a "hard systems" manner, while,

o Systems dynamics models would be considered probabilistic because they help assess how multiple futures may unfold, and specifically account for non-linear interactions (albeit not in a formal probability distribution). So in this case, systems dynamics models are probabilistic in a "soft systems" sense. 
- Similarly, when considering whether Bayesian networks and system dynamics models are probabilistic in how they address "stability, degeneracy and sub-optimization" (see Table 3 and Figure 2):

o Again, Bayesian networks are probabilistic in that they directly model the whole probability distributions to assess stability conditions and trade-offs, and multiple potential stability regimes, while.

o Systems dynamics models are probabilistic in the soft systems sense i.e., multiple stability regimes can be determined from running systems dynamics models in different scenarios, particularly as they preserve non-linear feedback effects (albeit in a different non-probabilistic formalism).

o That is, in both cases, self-organization can be assessed, but only with Bayesian networks are they assessed within a probability theory-based formalism.

- Accordingly, both techniques can be used to assess "adaptive capacity”, but unless agent-based formalisms are employed, then agency is indirectly modeled through the process of deciding on model constraints and configuration.

- Where Bayesian networks and systems dynamics models differ, for example, is that Bayesian networks are heterarchical (i.e., scale and value independent because it is based on a probability theory formalism), while systems dynamics models are hierarchical (i.e., bounded, inter-dependent systems and sub-systems) [65].

As illustrated in Table 3 and Figure 2 below, we can then assess how these techniques-individually (see Figure 2) and collectively (see Table 3)-address different properties of complex systems. The different colors in the aforementioned tables indicate what envelope or "footprint" of complex systems’ properties are addresses by a particular modeling technique.

Taken together, the collection of modeling techniques that are applied to the particular sustainability challenge that is being addressed can then be accounted for in terms of the span of complex systems' properties they address. More importantly, Table 3 and Figure 2 also help diagnose what properties of complex systems are not addressed by a particular modeling technique, and can help facilitate decision-making about what additional techniques may be necessary in order to "fill the gap” in addressing complex systems' properties in the overall modeling framework (and in respect of the collection of models that are selected).

Table 3 and Figure 2 facilitate the creation of a shared understanding of what complex systems' properties a particular modeling technique addresses, alone, and when combined with other modeling techniques (i.e.,. a complex systems' properties “envelope” or “footprint” is obtained). In this way, the proposed complexity-based modeling framework does not dictate particular modeling techniques, but helps locate them within a more general modeling framework where they can be compared with other techniques, and combined with other techniques, in order to address the particular modeling challenge being addressed. Shortcomings, as well as strengths of particular modeling techniques can then be evaluated in terms of a broader, complexity-based modeling framework. 
Table 3. Mapping properties of complex systems, and requirements for modeling transitions to sustainability, to selected modeling techniques.

\begin{tabular}{|c|c|c|c|c|c|c|c|c|c|c|c|c|c|c|c|c|}
\hline & \multicolumn{16}{|c|}{ Requirements for modeling transitions to sustainability } \\
\hline & \multicolumn{4}{|c|}{ Probabilistic } & \multicolumn{4}{|c|}{ Integrative } & \multicolumn{4}{|c|}{ Inclusive } & \multicolumn{4}{|c|}{ Adaptive } \\
\hline & $\mathrm{X}$ & $\mathrm{X}$ & & & $\mathrm{X}$ & $\mathrm{X}$ & $\mathrm{X}$ & $\mathrm{X}$ & $\mathrm{X}$ & $\mathrm{X}$ & $\mathrm{X}$ & $\mathrm{X}$ & $\mathrm{X}$ & $\mathrm{X}$ & $\mathrm{X}$ & $\mathrm{X}$ \\
\hline Modeling techniques & $\mathrm{ABN}$ & $\mathrm{BN}$ & ASD & SD & $\mathrm{ABN}$ & $\mathrm{BN}$ & ASD & SD & $\mathrm{ABN}$ & $\mathrm{BN}$ & ASD & SD & $\mathrm{ABN}$ & $\mathrm{BN}$ & ASD & $\mathrm{SD}$ \\
\hline Properties of complex systems & $\mathrm{ABN}$ & $\mathrm{BN}$ & ASD & SD & $\mathrm{ABN}$ & $\mathrm{BN}$ & ASD & SD & $\mathrm{ABN}$ & $\mathrm{BN}$ & ASD & SD & $\mathrm{ABN}$ & $\mathrm{BN}$ & ASD & SD \\
\hline Multi-agent & $\mathrm{X}$ & & $\mathrm{X}$ & & $\mathrm{X}$ & & $\mathrm{X}$ & & $\mathrm{X}$ & & $\mathrm{X}$ & & $\mathrm{X}$ & & $\mathrm{X}$ & \\
\hline Emergence \& self-organization & $\mathrm{X}$ & $\mathrm{X}$ & $\mathrm{X}$ & $\mathrm{X}$ & $\mathrm{X}$ & $\mathrm{X}$ & $\mathrm{X}$ & $\mathrm{X}$ & $\mathrm{X}$ & $\mathrm{X}$ & $\mathrm{X}$ & $\mathrm{X}$ & $\bar{X}$ & $\mathrm{X}$ & $\mathrm{X}$ & $\mathrm{X}$ \\
\hline Stability, degeneracy and sub-optimization & $\mathrm{X}$ & $\mathrm{X}$ & $\mathrm{X}$ & $\mathrm{X}$ & $\mathrm{X}$ & $\mathrm{X}$ & $\mathrm{X}$ & $\mathrm{X}$ & $\mathrm{X}$ & $\mathrm{X}$ & $\mathrm{X}$ & $\mathrm{X}$ & $\mathrm{X}$ & $\mathrm{X}$ & $\mathrm{X}$ & $\mathrm{X}$ \\
\hline Adaptive capacity & $\mathrm{X}$ & $\mathrm{X}$ & $\mathrm{X}$ & $\mathrm{X}$ & $\mathrm{X}$ & $\mathrm{X}$ & $X$ & $\mathrm{X}$ & $\mathrm{X}$ & $\mathrm{X}$ & $\mathrm{X}$ & $\mathrm{X}$ & $\mathrm{X}$ & $\mathrm{X}$ & $\mathrm{X}$ & $\mathrm{X}$ \\
\hline Undecidability & & & & & $\mathrm{X}$ & $\mathrm{X}$ & $\mathrm{X}$ & $\mathrm{X}$ & $\mathrm{X}$ & $\mathrm{X}$ & $\mathrm{X}$ & $\mathrm{X}$ & & & & \\
\hline Heterarchy & $\mathrm{X}$ & $\mathrm{X}$ & & & $\mathrm{X}$ & $\mathrm{X}$ & & & $\mathrm{X}$ & $\mathrm{X}$ & & & $\bar{X}$ & $\mathrm{X}$ & & \\
\hline Non-linearity & $\mathrm{X}$ & $X$ & $\mathrm{X}$ & $\mathrm{X}$ & $\mathrm{X}$ & $X$ & $\mathrm{X}$ & $\mathrm{X}$ & $\mathrm{X}$ & $X$ & $X$ & $\mathrm{X}$ & $\mathrm{X}$ & $X$ & $\mathrm{X}$ & $\mathrm{X}$ \\
\hline Anti-fragility \& creative capacity & & & & & & & & & $\mathrm{X}$ & $\mathrm{X}$ & $\mathrm{X}$ & $\mathrm{X}$ & $\mathrm{X}$ & $\mathrm{X}$ & $\mathrm{X}$ & $\mathrm{X}$ \\
\hline
\end{tabular}

ABN: Agent-Based Bayesian Networks; BN: Bayesian Networks; ASD: Agent-Based Systems Dynamics Models; SD: Systems Dynamics Models. The different colors in Table 3 indicates what envelope or "footprint” of complex systems' properties are addresses by each particular modeling technique, and helps differentiate between them. 
Figure 2. Evaluating different modeling techniques within the proposed modeling framework. (Each color corresponds to a particular modeling technique and indicates what envelope or "footprint” of complex systems' properties are addressed by it. It helps differentiate between the usefulness of different modeling techniques that were evaluated in Table 3.)

\begin{tabular}{|l|c|c|c|c|}
\hline \multirow{2}{*}{$\begin{array}{l}\text { Properties of } \\
\text { Complex Systems }\end{array}$} & \multicolumn{4}{|c|}{ Requirements for Modeling Transitions to Sustainability } \\
\cline { 2 - 5 } & Probabilistic & Integrative & Inclusive & Adaptive \\
\hline ABNs & $\mathrm{x}$ & $\mathrm{x}$ & $\mathrm{x}$ & $\mathrm{x}$ \\
\hline Multi-Agent & $\mathrm{x}$ & $\mathrm{x}$ & $\mathrm{x}$ & $\mathrm{x}$ \\
\hline $\begin{array}{l}\text { Emergence \& } \\
\text { Self-Organization }\end{array}$ & $\mathrm{x}$ & $\mathrm{x}$ & $\mathrm{x}$ & $\mathrm{x}$ \\
\hline $\begin{array}{l}\text { Stability, } \\
\text { Degeneracy and } \\
\text { Sub-Optimization }\end{array}$ & $\mathrm{x}$ & $\mathrm{x}$ & $\mathrm{x}$ & $\mathrm{x}$ \\
\hline Adaptive Capacity & $\mathrm{x}$ & $\mathrm{x}$ & $\mathrm{x}$ & $\mathrm{x}$ \\
\hline Undecideability & & $\mathrm{x}$ & $\mathrm{x}$ & \\
\hline Heterarchy & $\mathrm{x}$ & $\mathrm{x}$ & $\mathrm{x}$ & $\mathrm{x}$ \\
\hline Non-Linearity & $\mathrm{x}$ & $\mathrm{x}$ & $\mathrm{x}$ & $\mathrm{x}$ \\
\hline $\begin{array}{l}\text { Anti-Fragility \& } \\
\text { Creative Capacity }\end{array}$ & & & $\mathrm{x}$ & $\mathrm{x}$ \\
\hline
\end{tabular}

\begin{tabular}{|l|c|c|c|c|}
\hline \multirow{2}{*}{$\begin{array}{l}\text { Properties of } \\
\text { Complex Systems }\end{array}$} & \multicolumn{4}{|c|}{ Requirements for Modeling Transitions to Sustainability } \\
\cline { 2 - 5 } & Probabilistic & Integrative & Inclusive & Adaptive \\
\hline ASD & & $\mathrm{x}$ & $\mathrm{x}$ & $\mathrm{x}$ \\
\hline Multi-Agent & $\mathrm{x}$ & $\mathrm{x}$ & $\mathrm{x}$ & $\mathrm{x}$ \\
\hline $\begin{array}{l}\text { Emergence \& } \\
\text { Self-Organization }\end{array}$ & $\mathrm{x}$ & $\mathrm{x}$ & $\mathrm{x}$ & $\mathrm{x}$ \\
\hline $\begin{array}{l}\text { Stability, } \\
\text { Degeneracy and } \\
\text { Sub-Optimization }\end{array}$ & $\mathrm{x}$ & $\mathrm{x}$ & $\mathrm{x}$ & $\mathrm{x}$ \\
\hline $\begin{array}{l}\text { Adaptive } \\
\text { Capacity }\end{array}$ & $\mathrm{x}$ & $\mathrm{x}$ & $\mathrm{x}$ & $\mathrm{x}$ \\
\hline Undecideability & & $\mathrm{x}$ & $\mathrm{x}$ & \\
\hline Heterarchy & & & & $\mathrm{x}$ \\
\hline Non-Linearity & $\mathrm{x}$ & $\mathrm{x}$ & $\mathrm{x}$ & $\mathrm{x}$ \\
\hline $\begin{array}{l}\text { Anti-Fragility \& } \\
\text { Creative Capacity }\end{array}$ & & & $\mathrm{x}$ & $\mathrm{x}$ \\
\hline
\end{tabular}

\begin{tabular}{|l|c|c|c|c|}
\hline \multirow{2}{*}{$\begin{array}{l}\text { Properties of } \\
\text { Complex Systems }\end{array}$} & \multicolumn{4}{|c|}{ Requirements for Modeling Transitions to Sustainability } \\
\cline { 2 - 5 } & Probabilistic & Integrative & Inclusive & Adaptive \\
\hline BNs & $\mathrm{x}$ & $\mathrm{x}$ & $\mathrm{x}$ & $\mathrm{x}$ \\
\hline Multi-Agent & & & & $\mathrm{x}$ \\
\hline $\begin{array}{l}\text { Emergence \& } \\
\text { Self-Organization }\end{array}$ & $\mathrm{x}$ & $\mathrm{x}$ & $\mathrm{x}$ & $\mathrm{x}$ \\
\hline $\begin{array}{l}\text { Stability, } \\
\text { Degeneracy and } \\
\text { Sub-Optimization }\end{array}$ & $\mathrm{x}$ & $\mathrm{x}$ & $\mathrm{x}$ & $\mathrm{x}$ \\
\hline $\begin{array}{l}\text { Adaptive } \\
\text { Capacity }\end{array}$ & $\mathrm{x}$ & $\mathrm{x}$ & $\mathrm{x}$ & $\mathrm{x}$ \\
\hline Undecideability & & $\mathrm{x}$ & $\mathrm{x}$ & \\
\hline Heterarchy & $\mathrm{x}$ & $\mathrm{x}$ & $\mathrm{x}$ & $\mathrm{x}$ \\
\hline Non-Linearity & $\mathrm{x}$ & $\mathrm{x}$ & $\mathrm{x}$ & $\mathrm{x}$ \\
\hline $\begin{array}{l}\text { Anti-Fragility \& } \\
\text { Creative Capacity }\end{array}$ & & & $\mathrm{x}$ & $\mathrm{x}$ \\
\hline
\end{tabular}

\begin{tabular}{|l|c|c|c|c|}
\hline \multirow{2}{*}{$\begin{array}{l}\text { Properties of } \\
\text { Complex Systems }\end{array}$} & \multicolumn{4}{|c|}{ Requirements for Modeling Transitions to Sustainability } \\
\cline { 2 - 5 } & Probabilistic & Integrative & Inclusive & Adaptive \\
\hline SD & & $\mathrm{x}$ & $\mathrm{x}$ & $\mathrm{x}$ \\
\hline Multi-Agent & & $\mathrm{x}$ & $\mathrm{x}$ & $\mathrm{x}$ \\
\hline $\begin{array}{l}\text { Emergence \& } \\
\text { Self-Organization }\end{array}$ & $\mathrm{x}$ & $\mathrm{x}$ & $\mathrm{x}$ & $\mathrm{x}$ \\
\hline $\begin{array}{l}\text { Stability, } \\
\text { Degeneracy and } \\
\text { Sub-Optimization }\end{array}$ & & $\mathrm{x}$ & & \\
\hline $\begin{array}{l}\text { Adaptive } \\
\text { Capacity }\end{array}$ & $\mathrm{x}$ & $\mathrm{x}$ & $\mathrm{x}$ & $\mathrm{x}$ \\
\hline Undecideability & & $\mathrm{x}$ & $\mathrm{x}$ & \\
\hline Heterarchy & & & & $\mathrm{x}$ \\
\hline Non-Linearity & $\mathrm{X}$ & $\mathrm{x}$ & $\mathrm{x}$ & $\mathrm{x}$ \\
\hline $\begin{array}{l}\text { Anti-Fragility \& } \\
\text { Creative Capacity }\end{array}$ & & & & \\
\hline
\end{tabular}


In summary, the proposed modeling framework allows a research group to decide on a set of modeling techniques that fit a particular, context-specific sustainability challenge, by framing them within the broader context of what complex systems' properties are necessary to address in respect of the specific sustainability challenge being modeled.

\subsection{On Hyperstructures, Emergence and Explanation}

As the authors of [22] say: "Hyperstructures are multi-level emergent structures".

Hyperstructures are "scientifically legitimate explanations of complex systems" [22]. They separate "regularities from randomness in its input stream" [66] and hence can be regarded as the "internal model" of a complex adaptive system. Emergence, in this sense, constitutes the deviations in the "input stream" from what may be expected from the explanations tendered by the internal model(s) and/or model(s)/schemas [66] of reasoning that inform the formulation of hyperstructures. Moreover, Baas and Emmeche point out that, "The observational mechanism may be internal or external", so hyperstructures "can be found existing in objective as well as subjective reality" [22].

We hence refer to the collection of models that are used to "understand and explain" complex socio-ecological/social-ecological and/or socio-technical systems (i.e., their controls, functions, processes, behaviors and identities) as hyperstructures. A collection of soft (i.e., mental models such as scenarios, strategies, systems diagrams) models and hard (i.e., mathematical, statistical, computational) models are used to "understand and explain" behaviors at the whole and sub-system scales, and constitute the hyperstructures that pertain to a particular system or problem. These models or "schemas" [66], taken together-and which constitute the hyperstructures-can be overlapping or non-overlapping, equifinal or non-equifinal.

For example, where global climate change is concerned, no single model is definitive. Hence, a collection of "global climate models" (GCMs) is required to ensure rigor and robustness of projections. As a collection of hyperstructures, where models are underlaid by differing sets of assumptions and techniques, GCMs can be used to cross-verify equifinality, and to obtain deeper understanding of non-equifinal outcomes in different scenarios (i.e., through differences in models and underlying assumptions and techniques).

Moreover, the challenge of ensuring shared understanding is paramount. In this respect, Baas and Emmeche state that, " $(\mathrm{t})$ he point is to combine the notion of emergence and hierarchy into the notion of hyperstructure [22]. Our point of view ... is that wherever a problem, a situation, or a structure can be organized into a hyperstructure, this has an explanatory power”. As we have already outlined, emergence and hierarchy can be combined by insisting on heterarchy. Hence, hyperstructures that are (1) heterarchical, and supported by (2) adequate visualizations, can play an important role in engendering shared understanding of different and similar perspectives on how transitions to sustainability may take place.

Accordingly, the modeling framework we propose enables the selection and cross-comparison of modeling techniques that are used to formulate the hyperstructures (see Table 3, Figures 2 and 3), that as a group, are used to understand complex transitions to sustainability for a particular system/regime. In this way, the modeling approach ensures that the hyperstructures themselves adequately cater for complex systems’ properties. 
Figure 3. Model formulation and implementation process.

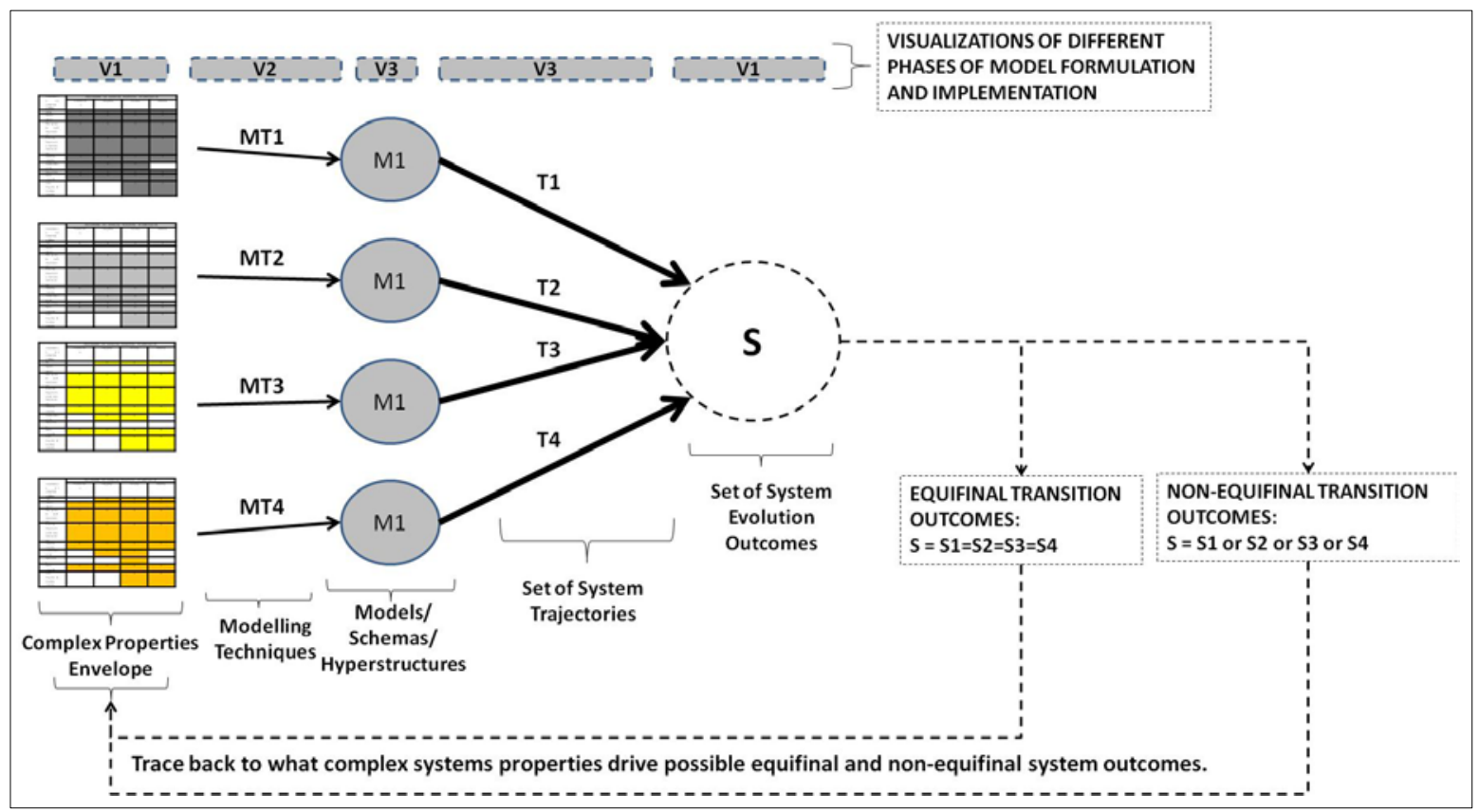

\subsection{A Complexity-Based Model Formulation and Implementation Process for Transitions to Sustainability}

The proposed complexity-based modeling framework is an open framework (i.e., not universal) where properties can be extended or shortened as the context dictates. Table 3 and Figure 2 determine the "envelope" of complex systems' properties that are individually and collectively addressed by individual modeling techniques, and the group of modeling techniques taken together-and the hyperstructures that result from their use-respectively. It determines how a set of hyperstructures can be assessed in respect of the extent to which they address complex systems' properties, and also indicates where the strengths and roles of different modeling techniques are best located in respect of complex systems' properties, that is; for a particular, specific sustainability challenge and the context within which it is considered.

The model formulation and implementation process that we propose is shown in Figure 3. It may be understood as a series of phases, namely:

- Evaluate potential modeling techniques in terms of their complex properties envelope (or "footprint"), and select a range of techniques that cover all potential complexities, or a specific set of complexities.

- Use specific techniques to formulate models of sub-systems and/or whole systems.

- Verify, validate and accredit models where necessary.

- Run models, observe system trajectories and determine set of potential system outcomes.

- Trace system outcomes back to the complex system properties (and the interdependencies associated with them) that drive possible equifinal and non-equifinal future system outcomes.

In this way, we can enable a complexity-based understanding of transitions to sustainability, that is; through understanding what behaviors manifest as a result of complex system properties, and the interdependencies associated with these properties at a systems level. 
Moreover, each phase is supported through powerful visualizations and graphical aids. Through using powerful visualizations of complex systems' properties and behaviors to understand transition trajectories to sustainability, high levels of "shared understanding" can be engendered amongst researchers of different disciplines, stakeholders, decision-makers and policy-makers. This shared understanding of transitions itself-e.g., through scenarios, forecasts, system constraints, key drivers of system evolution such as functions, controls, processes, and complex systems' properties and behaviors - can serve as a strong basis for inclusive, transparent and representative learning, participation, negotiation and coordination between different sectors, stakeholders and decision-makers. This is especially important where the negotiation of sub-optimization system profiles, as well as resolving undecidables is concerned.

Furthermore, in respect of the need for a plurifocal approach (see Section 1.2) towards adaptive management of transitions, both equifinal (same ends, different trajectories) and non-equifinal (different ends, different trajectories) models can be incorporated and compared within the framework:

- Where equifinal models are concerned-i.e., models that purposively seek to realise a particular outcome or set of outcomes such as sustainability criteria-different properties of complex systems can be tested and/or evaluated within the proposed modeling approach by using different modeling techniques to evaluate equifinal models and cross-verify them. Moreover, this approach may also help point out or discover different ways of arriving at the same outcome, through a deeper appreciation of the complexities underlying systems behavior and evolution.

- Where non-equifinal models are concerned the approach allows for divergent outcomes to be assessed and/or evaluated and cross-compared within a complexity-based framework where complex systems’ properties, and their impacts, are understood.

That is, the modeling framework enables a plurifocal approach (multiple system configurations, multiple system drivers and multiple futures), which is also rigorous in addressing an "envelope" of complex systems' properties that are essential for understanding and negotiating transitions to sustainability. These "properties", and how they are framed, also help shift the focus of modeling towards understanding complex properties and the interdependencies associated with them instead of an exclusive focus on "parts” and “mechanisms”.

\section{Conclusions}

The proposed modeling framework can be used to assess the extent to which different modeling techniques address complex systems' properties that are important for understanding complex transitions to sustainability. The framework: (1) elucidates and visualizes which complex systems' properties are addressed by particular modeling techniques; (2) allows for gaps to be identified; and (3) can allow for adaptively managing models and modeling techniques as real-world transitions unfold.

\section{Acknowledgments}

The authors would like to acknowledge the National Research Foundation (NRF), which provided the funding for a postdoctoral fellowship under which this research was conducted. In addition, the authors would like to acknowledge the support of the School of Public Leadership in the Faculty of 
Economic and Management Sciences, Stellenbosch University, South Africa. This research is dedicated to the memory of the late Professor Paul Cilliers, whose contribution to the field of complexity remains a major source of inspiration to many students, academics and intellectual across the world.

\section{Author Contributions}

Camaren Peter is the lead author of this paper. It was conducted under the supervision and guidance of Mark Swilling, who hosted the NRF Fellowship under which Peter conducted the research presented in this paper.

\section{Conflicts of Interest}

The authors declare that no conflict of interest exists in respect of the submitted manuscript. Although this research builds upon previous research conducted during the course of Ph.D. studies, the research submitted in this paper is substantively new and represents a significant advancement of previous arguments.

\section{References}

1. Levin, S.A. Learning to live in a global commons: Socioeconomic challenges for a sustainable environment. Ecol. Res. 2006, 21, 328-333.

2. Folke, C.; Hahn, T.; Olsson, P.; Norberg, J. Adaptive governance of social-ecological systems. Annu. Rev. Environ. Resour. 2005, 30, 441-473.

3. An, L. Modeling human decisions in coupled human and natural systems: Review of agent-based models. Ecol. Model. 2012, 229, 25-36.

4. Liu, J.; Dietz, T.; Carpenter, S.R.; Alberti, M.; Folke, C.; Moran, E.; Pell, A.N.; Deadman, P.; Kratz, T.; Lubchenco, J.; et al. Complexity of coupled human and natural systems. Science 2007, 317, 1513-1516.

5. Mathies, M., Malchow, H., Kriz, J., Eds. Integrative Systems Approaches to Natural and Social Dynamics; Springer: Berlin, Germany, 2001.

6. Loorbach, D.; Rotmans, J. Managing Transitions for Sustainable Development. In Understanding Industrial Transformation; Olsthoorn, X., Wieczorek, A.J., Eds.; Springer: Berlin, Germany, 2006; Volume 44, pp. 187-206.

7. Von Bertalanffy, L.; Hempel, C.G.; Bass, R.E.; Jonas, H.; General systems theory: A new approach to the unity of science. Hum. Biol. 1951, 23, 302-361.

8. Holland, J.H. Hidden Order: How Adaptation Builds Complexity; Addison-Wesley: Reading, MA, USA, 1995.

9. Midgley, G., Ed. Systems Thinking; Sage Publications: Thousand Oaks, CA, USA, 2003.

10. Seidl, R.; Brand, F.S.; Stauffacher, M.; Krütli, P.; Le, Q.B.; Spörri, A.; Meylan, G.; Moser, C.; González, M.B.; Scholz, R.W. Science with society in the antropocene. Ambio 2013, 42, 5-12.

11. Van Kerkhoff, L.; Lebel, L. Linking knowledge and action for sustainable development. Annu. Rev. Environ. Resour. 2006, 31, 445-477. 
12. Voinov, A.; Bousquet, F. Modelling with stakeholders. Environ. Model. Software 2010, 25, 1268-1281.

13. Wiek, A.; Farioli, F.; Fukushi, K.; Yarime, M. Sustainability science: Bridging the gap between science and society. Sustain. Sci. 2012, 7, 1-4.

14. Chu, D.; Strand, R.; Fjelland, R. Theories of complexity. Complexity 2003, 8, 19-30.

15. Heylighen, F.; Cilliers, P.; Gershenson, C. Complexity and Philosophy. In Complexity, Science and Society; Blogg, J., Geyer, R., Eds.; Radcliffe Publishing: Oxford, UK, 2007.

16. Checkland, P.B.; Scholes, J. Soft Systems Methodology in Action; Wiley: Chichester, UK, 1990.

17. Gershenson, C.; Heylighen, F. When Can We Call a System Self-Organizing? In Advances in Artificial Life, 7th European Conference, ECAL 2003, Dortmund, Germany, September 14-17, 2003, Proceedings; Banzhaf, W., Christaller, T., Dittrich, P., Kim, J.T., Ziegler, J., Eds.; Springer: Berlin, Germany, 2003; pp. 606-614.

18. Weaver, W. Science and complexity. Am. Sci. 1948, 36, 536-544.

19. Cariani, P. A Review of Emergence and Artificial life. In Artificial Life II, Vol. X of Santa Fe Institute Studies in the Sciences of Complexity; Langton, C., Taylor, C., Farmer, J., Rasmussen, S., Eds.; Addison-Wesley: Reading, UK, 1991; pp. 775-797.

20. Cilliers, P. Boundaries, hierarchies and networks in complex systems. Int. J. Innovat. Manag. 2001, doi:10.1142/S1363919601000312.

21. Cilliers, P. Complexity Theory as a General Framework for Sustainability Science. In Exploring Sustainability Science: A Southern African Perspective; 1st ed.; Burns, M., Weaver, A., Eds.; Sun Press: Stellenbosch, South Africa, 2008; pp. 39-57.

22. Baas, N.A.; Emmeche, C. On emergence and explanation. Intellectica 1997, 25, 67-83.

23. Geels, F.W.; Schot, J. Typology of sociotechnical transition pathways. Res. Policy 2007, 36, 399-417.

24. Pepper, S.C. Emergence. J. Phil. 1926, 23, 241-245.

25. Islam, G.; Zyphur, M.J.; Beal, D.J. Can a Whole be Greater than the Sum of its Parts? A Critical Appraisal of "Emergence”; Ibmec Working Paper; Ibmec: Sao Paulo, Brazil.

26. Walker, B.; Holling, C.S.; Carpenter, C.R.; Kinzig, A. Resilience, adaptability and transformability in social-ecological systems. Ecol. Soc. 2004, 9, Article 5.

27. Ashby, W.R. Principles of the Self-Organizing System. In The Principles of Self-organization: Transactions of the University of Illinois Symposium; Von Foerster, H., Zopfr, G.W., Jr., Eds.; Pergamon Press: London, UK, 1962; pp. 255-278.

28. Giddens, A. The Constitution of Society: Outline of the Theory of Structuration; Polity Press: Cambridge, UK, 1984.

29. Stern, P.C. Toward a coherent theory of environmentally significant behaviour. J. Soc. Issues 2000, 5, 407-424.

30. Richardson, K.A. Systems theory and complexity: Part 3. Emergence 2005, 7, 104-1144.

31. Skyttner, L. General Systems Theory: Ideas and Applications; World Scientific: River Edge, NJ, USA, 2001.

32. Taleb, N.N. Antifragile; Allen Lane/Penguin Books: London, UK, 2012.

33. Richardson, K.A. On the Limits of Bottom-Up Computer Simulation: Towards a Nonlinear Modelling Culture. In Proceedings of the 36th Hawaii International Conference on System Sciences, Hawaii, CA, USA, 6-9 January 2003. 
34. Max-Neef, M.A. Foundations of transdisciplinarity. Ecol. Econ. 2005, 53, 5-16.

35. Nicolescu, S. Stephane Lupesco, L'homme et l'euvre; La Rochet: Paris, France, 1999. (In French).

36. Banisch, M. Derrida, Schmitt and the Essence of the Political; Refereed Paper Presented as Part of the Political Theory Stream Jubilee Conference of the Australasian Political Studies Association; Australian National University: Canberra, Australia, 2002.

37. Derrida, J. Force of Law: “The Mystical Foundation” of Authority. In Deconstruction and the Possibility of Justice; Cornell, D., Rosenfeld, M., Carlson, D., Eds.; Routledge: New York, NY, USA, 1992.

38. Gillaume, P.; Tranouez, P.; Bertelle, C.; Olivier, D.; Lerebourg, S. Methodology for Holarchic Ecosystem Model Based on Ontological Tool. In Proceedings of the European Simulation and Modelling Conference, Paris, France, October 2004.

39. Heylighen, F.; Joslyn, C.; Turchin, V. Principia cybernetic web. Available online: http:// pespmc1.vub.ac.be/ASC/HETERARCHY.html (accessed 28 November 2013).

40. Gunderson, L.H. Ecological resilience-In theory and application. Annu. Rev. Ecol. Syst. 2000, 31, 425-439.

41. Folke, C.; Carpenter, S.; Elmqvist, T.; Gunderson, L.; Holling, C.S.; Walker, B.; Bengtsson, J.; Berkes, F.; Colding, J.; Danell, K.; et al. Resilience and Sustainable Development: Building Adaptive Capacity in a World of Transformations, International Council for Science; International Council for Science (ICSU): Paris, France, 2002.

42. Gunderson, L.H., Holling C.S., Eds. Panarchy: Understanding Transformations in Human and Natural Systems; Island Press: Washington, DC, USA, 2002.

43. Peterson, G.D.; Allen, C.R.; Holling, C.S. Ecological resilience, biodiversity and scale. Ecosystems 1998, 1, 6-18.

44. Peter, C. Bayesian Participatory-Based Decision Analysis: An Evolutionary, Adaptive Formalism for Integrated Analysis of Complex Challenges to Social-Ecological Systems Sustainability. Ph.D. Thesis, University of Cape Town, Cape Town, South Africa, 5 June 2010.

45. Holling, C.S. From complex regions to complex worlds. Ecol. Soc. 2004, 9, Article 11.

46. Grin, J.; Rotmans, J.; Schot, J. Transitions to Sustainable Development: New Directions in the Study of Long Term Transformative Change; Routledge Studies in Sustainability Transitions; Routledge: New York, NY, USA, 2010.

47. Fischer-Kowalski, M.; Swilling, M. Decoupling Natural Resource Use and Environmental Impacts from Economic Growth, UNEP International Panel for Sustainable Resource Management (IRP). Available online: http://www.unep.org/resourcepanel/decoupling/files/pdf/ decoupling_report_english.pdf (accessed on 28 November 2013).

48. Ehrlich, P.R.; Levin, S.A. The evolution of norms. PLoS. Biol. 2005, 6, 943-948.

49. Ashby, W.R. An Introduction to Cybernetics; Methuen: London, UK, 1964.

50. Peterson, G.D.; Cumming, G.S.; Carpenter, S.R. Scenario planning: A tool for conservation in an uncertain world. Conservat. Biol. 2003, 17, 358-366.

51. Kates, R.W.; Clarke, W.C. Expecting the unexpected. Environment 1996, 38, 6-11.

52. Malhotra, Y. Knowledge Management for Organizational White-Waters: An Ecological Framework. Available online: http://community-intelligence.com/files/Malhotra\%20-\%20Knowledge\% 20Management\%20for\%20organisational\%20white-waters.pdf (accessed on 28 November 2013). 
53. Holling, C.S.; Gunderson, L.H.; Ludwig, D. In Quest of a Theory of Adaptive Change. In Panarchy: Understanding Transformations in Human and Natural Systems; Gunderson, L.H., Holling, C.S., Eds.; Island Press: Washington, DC, USA, 2002; pp. 3-24.

54. Holling, C.S. Resilience and stability of ecological systems. Annu. Rev. Ecol. Syst. 1973, 4, 1-23.

55. Taleb, N.N. The Black Swan: The Impact of the Highly Improbable; Penguin Books: London, UK, 2007.

56. Holling, C.S.; Gunderson, L.H. Resilience and Adaptive Cycles. In Panarchy: Understanding Transformations in Human and Natural Systems; Gunderson, L.H., Holling, C.S., Eds.; Island Press: Washington, DC, USA, 2002; pp. 25-62.

57. Hodson, M.; Marvin, S.; Robinson, B.; Swilling, M. Reshaping urban infrastructure material flow analysis and transitions analysis in an urban context. J. Ind. Ecol. 2012, 16, 789-800.

58. Holling, C.S.; Gunderson, L.H.; Peterson, G.D. Sustainability and Panarchies. In Panarchy: Understanding Transformations in Human and Natural Systems; Gunderson, L.H., Holling, C.S., Eds.; Island Press: Washington, DC, USA, 2002; pp. 63-102.

59. Clarke, K. The Limits of Simplicity: Toward Geocomputational Honesty in Urban Modelling. In the Proceedings of the 7th International Conference on Geocomputation, Southampton, UK, 8-10 September 2003.

60. Keynes, J.M. A Treatise on Probability; MacMillan and Company: London, UK, 1921.

61. Zellmer, A.J.; Allen, T.F.H.; Kesseboehmer, K. The nature of ecological complexity: A protocol for building the narrative. Ecol. Complex. 2006, 3, 171-182.

62. Pahl-Wostl, C. The implications of complexity for integrated resource management. Environ. Model. Software. 2007, 22, 561-569.

63. Carnap, R. Statistical and Inductive Probability. Available online: http://fitelson.org/probability/ carnap_saip.pdf (accessed on 28 November 2013).

64. Von Plato, J. Creating Modern Probability: Its Mathematics, Physics and Philosophy in Historical Perspective; Cambridge University Press: Cambridge, UK, 1994.

65. Liu, J.; Lee, E.A. Component-Based Hierarchical Modeling of Systems with Continuous and Discrete Dynamics. In Proceedings of the 2000 IEEE International Symposium on Computer-Aided Control System Design, Anchorage, AK, USA, 25-27 September 2002; pp. 95-100.

66. Gell-Mann, M. The Quark and the Jaguar; W. H. Freeman and Company: New York, NY, USA, 1994.

(C) 2014 by the authors; licensee MDPI, Basel, Switzerland. This article is an open access article distributed under the terms and conditions of the Creative Commons Attribution license (http://creativecommons.org/licenses/by/3.0/). 